\title{
Las movilidades poblacionales y su impacto territorial en la estructura espacial de las ciudades turísticas. El caso de San Carlos de Bariloche
}

Víctor Medina. Fundación Bariloche, San Carlos de Bariloche, Argentina.

RESUMEN | Partiendo de las características que presenta el crecimiento urbano de una ciudad turística de Argentina, San Carlos de Bariloche, el propósito inicial de este artículo es relacionar su fisonomía espacial con las migraciones de amenidad y los procesos de naturbanización. Ambos fenómenos refieren al impacto de las movilidades poblacionales en entornos naturales privilegiados y de gran atractivo turístico. En el caso de la localidad andina, se postula que estas movilidades supusieron una incidencia histórica en las características de su expansión territorial que todavía perduran. Para dilucidar su manifestación más reciente, se analizarán algunas de estas características en expresiones que permitan descubrir la reiteración de lógicas estructurales en el crecimiento de la urbe. Esto permitirá sembrar algunos interrogantes respecto a la tipicidad de su suelo $-\mathrm{y}$ de otras ciudades de entornos ambientales singulares- y las rentas que les podrían estar asociadas.

PALABRAS CLAVE $\mid$ migración, morfología urbana, medioambiente urbano.

ABSTRACT | The initial purpose of this study is to relate physiognomy space with amenity migrations and naturbanizacion processes, based on the characteristics of the urban growth of San Carlos de Bariloche, a tourist city in Argentina. Both phenomena refer to the impact of population mobility in privileged natural environments and great tourist attraction. In the case of the Andean town, it is claimed that this mobility accounts for a historical impact in the characteristics of territorial expansion that still prevail. To elucidate its latest manifestation, the study will discuss some of these features in expressions that allow to discover the reiteration of structural patterns in the growth of the city. This will help raise questions concerning typical features of this zone -and from other cities of different environmentsand the rents that might be associated.

KEYWORDS | migration, urban morphology, urban environment. 


\section{Introducción}

San Carlos de Bariloche es una ciudad turística ubicada al sudoeste de la provincia de Río Negro, al norte de la Patagonia argentina. Dueña de un entorno natural único, cuenta con sobrados lagos y cuencas hídricas que le permiten, junto al característico despliegue montańoso circundante, erigirse como un lugar de ensueño paisajísticamente privilegiado. Estas propiedades, históricamente celebradas, fueron también las que sentaron las bases materiales de su formación y promoción como destino turístico.

Sin embargo, sus bondades naturales se convirtieron prontamente en objeto de voraces apetencias que condicionaron la dirección del crecimiento de la urbe desde ámbitos lejanos a sus límites geográficos y jurisdiccionales. Ello ocurrió sea porque Bariloche en sus orígenes formaba parte de la jurisdicción de los antiguos territorios nacionales o porque, una vez encuadrada en los límites provinciales, la autonomía y potestad local se subsumieron a otros intereses igualmente alejados del arraigo local y la experiencia cotidiana de vivir en la ciudad. En este marco, cabe pensar que sus atractivos naturales diferenciales la hicieron presa de un mercado inmobiliario que trascendió las fronteras de la localidad. El hecho de que el crecimiento de San Carlos de Bariloche históricamente haya avanzado hacia el oeste, en una extensión cercana a los 45 kilómetros sobre la costa del lago Nahuel Huapi, y cuente con una superficie ejidal de 27.455 hectáreas (mayor, incluso, que la de la capital del país, Buenos Aires), consigue instalar como interrogante el rol del medio natural en las lógicas de ocupación territorial, permitiendo avizorar su incidencia en la determinación de la estructura espacial.

Esta influencia del medio natural en la configuración de los patrones de crecimiento urbano de San Carlos de Bariloche, que hace unos ańos se buscó contener a través de planes y códigos y reorientar hacia otras áreas de la ciudad, abre las puertas para pensar en la localización del suelo, su explotación y las rentas concomitantes. El atractivo turístico particular de la ciudad como destino de montańa pareciera ser una de las claves para comprender los intereses inmobiliarios puestos en juego. En estos términos, ¿qué fenómenos podrían haberse dado cita en la estructuración espacial de su territorio y en las características que asumió el proceso de urbanización de San Carlos de Bariloche? Y además, tomando en cuenta las características de su suelo, ¿̇cómo podrían estar operando en la actualidad, cuando el valor de su apropiación pareciera definirse por las cualidades naturales del ambiente y su entorno paisajístico?

Para abordar estas cuestiones se consideró apropiado utilizar un enfoque metodológico predominantemente cualitativo, basado en la revisión bibliográfica, el análisis documental y la realización de entrevistas en profundidad a informantes clave. Complementariamente se emplearon datos cuantitativos provistos por diferentes organismos públicos, destinados a estimar someramente la dinámica inmobiliaria reciente. 


\section{El nacimiento de una ciudad turística}

Los contornos espaciales de San Carlos de Bariloche, tal como se la conoce hoy en las derivaciones que ha supuesto el crecimiento urbano y, asociado a ello, su entronización como centro de atracción turística, reconocen un origen externo en la gestión de Parques Nacionales. En efecto, el hecho de comenzar a ser una ciudad turística tuvo que ver con decisiones que no necesariamente involucraron una dinámica local, si se entiende por ello la identificación de necesidades surgidas en el seno de una comunidad establecida y con intereses comunes. En este sentido, Parques Nacionales se constituyó, en la década de los treinta del siglo pasado, en el principal agente que contribuyó a la construcción turística de una ciudad que se encontraba en los límites territoriales del parque Nahuel Huapi. Como organismo público dependiente del gobierno nacional, lo hizo a partir de la realización de obras de infraestructura en el casco céntrico y sus adyacencias, con la construcción del centro cívico y la catedral, entre otras obras de arquitectura que pretendieron definir la fisonomía de la llamada Suiza argentina. Este impulso a la actividad turística, que buscó a su vez consolidar una pretendida y temprana identidad urbana, no era ajeno a motivos relacionados con el fortalecimiento de las fronteras territoriales de un Estado-Nación aún en ciernes. Esta ajenidad marcó la impronta de una ciudad cuya funcionalidad se basaba en intereses supralocales que remarcaban su importancia para la dinámica de otros órdenes, turísticos y/o fronterizos, en razón de los cuales se terminó definiendo la orientación de su crecimiento.

La necesidad de argentinizar y ocupar un territorio podría explicar por qué la gestión de Parques Nacionales permitió el fraccionamiento de vastas hectáreas de lo que posteriormente, con la extensión de su jurisdicción, pasaría a formar parte del ejido territorial de San Carlos de Bariloche, condicionando las posibilidades futuras de planeamiento urbano (anexando, junto a las nuevas tierras, los fraccionamientos dispersos). Pero también concurrieron otros intereses que a mediados del siglo xx definieron la localización de estos fraccionamientos: no fue casual que los primeros loteos tuvieran lugar en las áreas boscosas y lacustres de mayor disfrute paisajístico al oeste del casco céntrico. Esto involucró un modo de dividir la tierra, desorganizado y carente de previsión, que dictó la pauta rústica y desmesurada de apropiación de estas áreas.

No había regulaciones, prácticamente eran hechas sin Código en ese momento. ${ }^{1}$ Por ejemplo, hay loteos en casi todo el oeste, que son del cincuenta y pico, que es la manzana con los lotes y las calles; sin equipamiento, sin infraestructura de servicios, sin espacio verde, sin reserva fiscal, sin nada. Por eso te digo, esto se constituye legalmente en el cuarenta, cincuenta, sesenta y parte del setenta, te diría yo.

(Orlandi, 2010, entrevista)

Vos tenías una tierra grande y hacías un proyecto de subdivisión, con unas calles y salías a vender lotes. Loteaban en península San Pedro 700 metros en pleno bosque;

1 De hecho lo eran, puesto que los primeros códigos, de planeamiento y de edificación, se sancionaron en 1980 . 
en Villa Llao Llao, ${ }^{2}$ lo mismo. Son cosas sin mucha normativa. Era territorio nacional, no había una provincia. (Pena, 2012, entrevista)

La mayor parte de los fraccionamientos se ejecutaron entre las décadas de 1940 y 1950, cuando todavía Parques Nacionales dirigía los destinos de San Carlos de Bariloche. De hecho, del total de subdivisiones realizadas en la ciudad, poco más del 60\% tuvo lugar en esos ańos (aproximadamente, 2.260 hectáreas); es más, solo en la década de 1940, se fraccionó el 38\% (1.280 hectáreas). Se subdividió tierra en distintos puntos geográficos -sur y este, por ejemplo-, pero la mayoría se localizó en sitios de costa de lago, preferentemente cercanos al centro, y en sitios que, aun estando más alejados de este, formaban parte del entorno de los principales atractivos turísticos, lo cual explica también los distintos tamańos de los lotes creados (de entre 400 y $3.800 \mathrm{~m}^{2}$, aproximadamente). La mayor accesibilidad que supuso durante esos ańos el asfaltado de la principal avenida que corre hacia el oeste -la avenida Bustillo- consolidó el interés inmobiliario en esa dirección y la suburbanidad que posteriormente adquiriría la ciudad (a lo que también contribuyó el otro conector vial que, de forma paralela, atraviesa la parte oeste de la ciudad, la avenida Pioneros) (Abaleron, 1992). Los ańos cuarenta y cincuenta constituyeron también un periodo en el que se consolidó prácticamente la totalidad de su ejido actual: de una superficie de 7.809 hectáreas fijada por decreto del Poder Ejecutivo nacional en 1929, ascendió a 13.622 en 1944 y a 22.027 en 1952.

A partir de la década de los sesenta, cuando ya muchas de las decisiones vinculadas al planeamiento de Bariloche estuvieron a cargo del Estado local luego de la provincialización de Río Negro, los fraccionamientos se mantuvieron (fueron loteadas cerca de 270 hectáreas). Con menos tierras disponibles, se concentraron en algunas zonas céntricas y en entornos naturales del área oeste, muchos incluso cercanos a la costa del lago Gutiérrez, en predios de entre 700 y $2.500 \mathrm{~m}^{2}$ (Abaleron, 1992). En conjunto, tampoco eran subdivisiones que guardaran relación con las necesidades habitacionales de la ciudad que, aunque sostenía un crecimiento demográfico continuo desde 1947, en 1960 apenas contaba en toda la zona urbana con 15.995 pobladores.

En el área desde el límite oeste del casco urbano y hasta Playa Bonita ${ }^{3}$ había en 19601.249 personas, en Llao 376, y en la Península de San Pedro 274. Esto es un total de 17.894 habitantes, cifra que está aún por debajo del total del ejido puesto que falta sumarle parte de la población rural, que para el total del departamento ascendía a 5.179 personas. (Abaleron \& Del Popolo, 1994, p. 5)

De esta forma, a comienzos de la década de 1960 buena parte de la población local se encontraba dispersa en grandes distancias territoriales y rodeada de muchos espacios vacantes, lo cual denotaba dos situaciones: la intención de ocupar un entorno climático privilegiado, residiendo en él; y la espera por la oportunidad propicia para vender la tierra. Reafirmando estas tendencias, las cifras del censo nacional de 1970 señalaban que la densidad poblacional era de 1,3 personas por hectárea (Abaleron, 1992, p. 26).

2 Áreas naturales de gran atractivo turístico y paisajístico ubicadas al oeste del ejido de San Carlos de Bariloche, a 25 kilómetros del casco céntrico.

3 Aproximadamente a siete kilómetros al oeste del casco céntrico. 
En las siguientes imágenes aéreas puede observarse el rumbo que comenzó a tomar el proceso de urbanización en el periodo de subdivisiones comprendido entre los años 1940 y la década de 1970. Se destacan inicialmente las líneas de subdivisión -caminos, calles y manzanas- en el casco céntrico y posteriormente, ya en los años setenta, el avance discontinuo hacia algunos sectores de las áreas oeste, sur y sudoeste del ejido.

FIGURA I $\mid$ Fotografía aérea de San Carlos de Bariloche, 1940

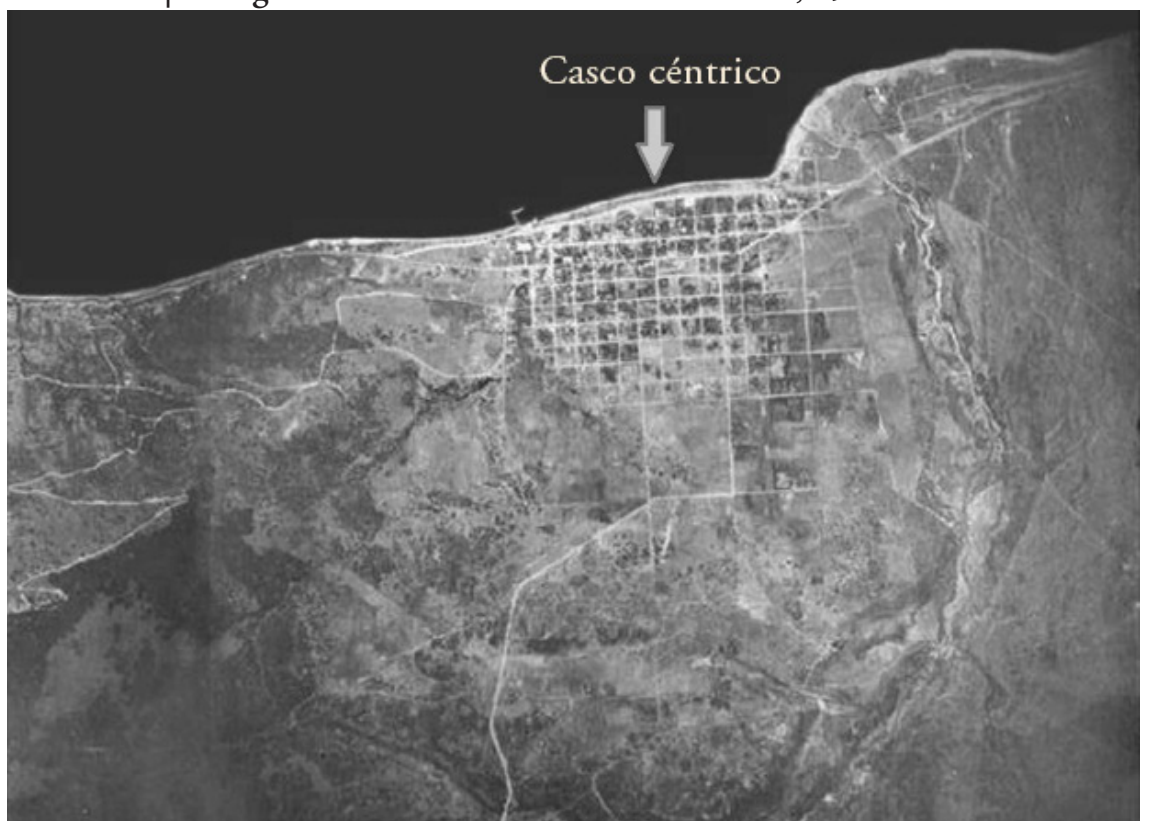

FUENTE MUNICIPIO DE SAN CARLOS DE BARILOCHE

Sin embargo, antes de que entrara en vigencia el plan director de 1979 -o quizás por este motivo-, durante esta década continuaron los fraccionamientos, aunque en una medida que en promedio tendió a ser menor que la registrada en años anteriores, loteándose aproximadamente 203 hectáreas (Abaleron, 1992). Asimismo, si bien muchos de estos nuevos loteos todavía se localizaban al oeste, las tendencias de parcelamiento comenzaban a dirigirse al este del ejido. De clima seco y características esteparias, esta área comenzó lentamente a ser loteada durante las siguientes dos décadas y hasta prácticamente fin de siglo. ${ }^{4}$ Cabe agregar, no obstante, que la superficie parcelada nunca alcanzó la expansión territorial que tuvo en el oeste, ya que históricamente (hasta hace unos años) siempre se la desestimó como sitio de potenciales asentamientos habitacionales. 
Figura 2 Fotografía aérea de San Carlos de Bariloche, 1970

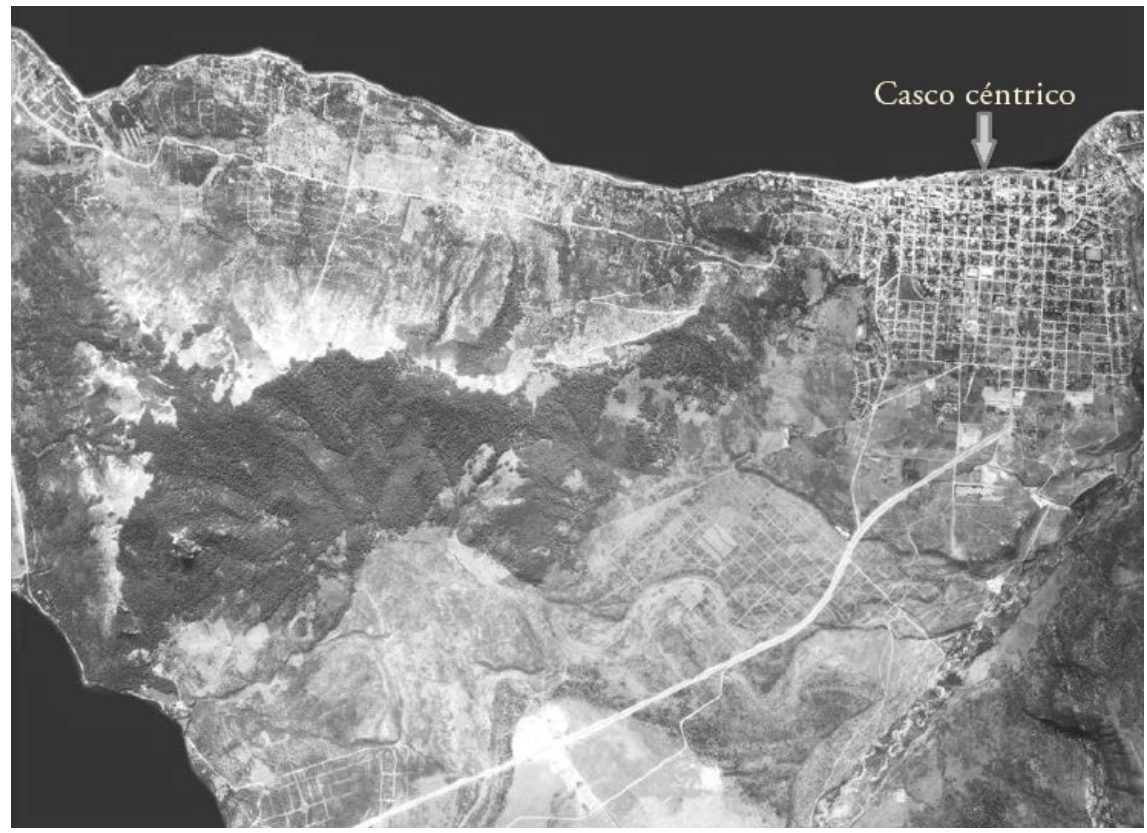

FUENTE MUNICIPIO DE SAN CARLOS DE BARILOCHE

FIGURA 3 | Fraccionamientos realizados en San Carlos de Bariloche, 1940-2000

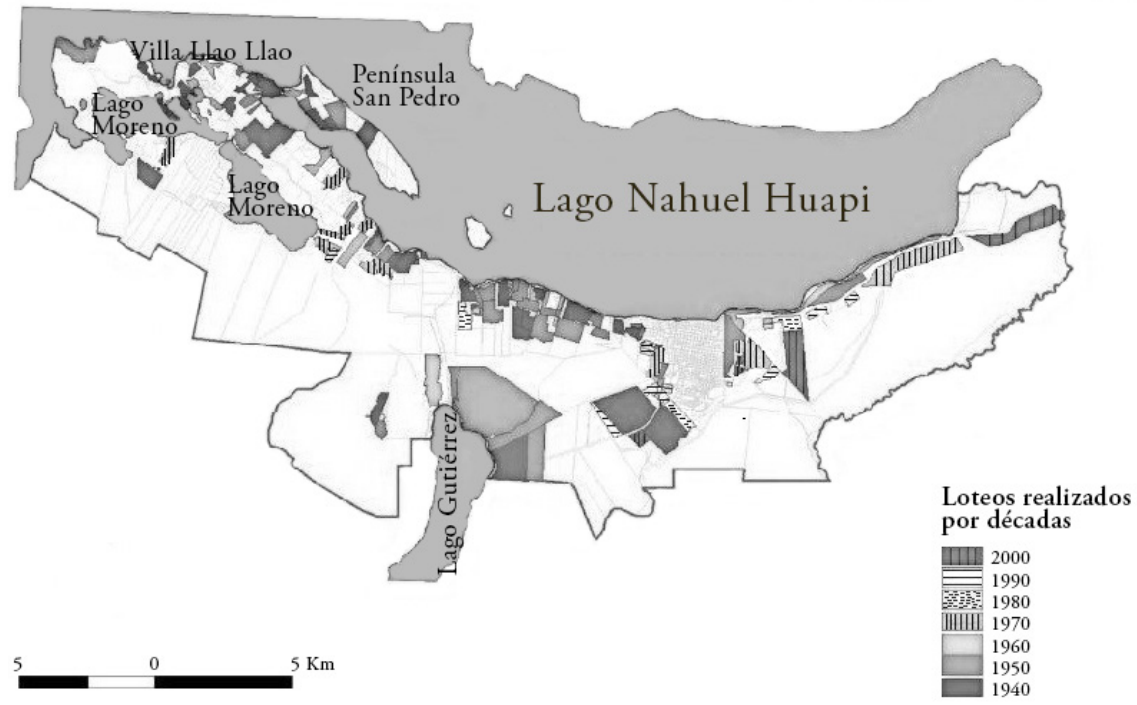

FUENTE MUNICIPIO DE SAN CARLOS DE BARILOCHE 
Principalmente, el interés inmobiliario se concentró en áreas próximas a las costas de los lagos, donde se ubican los paisajes más vistosos y la trama boscosa es mayor y más diversa, circunstancia que, eventualmente, sellaría las coordenadas direccionales de la expansión urbana. El crecimiento poblacional de la ciudad, que comenzó a ser expresamente manifiesto durante la consolidación de su perfil turístico a mediados del siglo $\mathrm{xx}$, con "tasas de crecimiento medio anual muy altas que duplicaron las de la provincia (entre 1947 y 1980) e inclusive triplicaron las del país (entre 1947 y 1991)” (Matossian, 2008, p. 3), lejos de desvanecer estas tendencias las afianzó durante la década de 1990, concentrando población en varios aglomerados ubicados al oeste y en cercanías a la costa de los lagos. ${ }^{5}$ Incluso ya en la década de 2000, a pesar de una incipiente expansión del área este, los espacios suburbanos de mayor densidad, de ocupación alta y media, continuaban localizándose en determinadas áreas suburbanas de aquella área (amén del casco céntrico y de sus barrios aledaños, que es la zona más densamente poblada).

\section{Algunas características de su crecimiento}

Si se quisiera ensayar alguna clase de semblanza sucinta de lo que puede describirse como crecimiento urbano en San Carlos de Bariloche, habría que comenzar empleando el término sprawl o urbanización difusa. Esto es, un tipo de crecimiento disperso, poco compacto y con tendencia a la suburbanización, en el que además es estrecho, y se asume fraternal, el contacto con la naturaleza (Anton Clavé, 1998). Históricamente, la ocupación del territorio en esta ciudad se ha distinguido por la dispersión generalizada de asentamientos habitacionales en los que puede reconocerse, acaso como rasgo sintomático, la dotación parcial de infraestructuras y equipamiento urbano y la insuficiencia en la calidad de los servicios que debe prestar el municipio (como la recolección de basura y la limpieza general) a lo largo de un extenso ejido de poco más de 27.000 hectáreas. En este sentido, el carácter disperso de sus propiedades urbanas propende a encuadrarse en la definición de 'ciudad difusa' que formula Francesco Indovina (2007):

La ciudad difusa, fórmula que como es obvio constituye una contradicción en términos, se da cuando una determinada y amplia porción de territorio urbanizado ofrece gran abundancia y variedad de funciones, caracterizándose por una amplia dotación de servicios pese a que estén esparcidos por el territorio, y cuando -este es el principal requisito- es utilizada por la población allí asentada como si de una ciudad se tratara. Es la cuestión de los equipamientos y de su uso lo que justifica dicha denominación. (p. 18)

En San Carlos de Bariloche es importante tener en cuenta estos aspectos, sobre todo en relación con las motivaciones que pudieron haber signado la localización residencial de sus habitantes en entornos naturales distantes entre sí y asimétricamente dotados de servicios urbanos. Ello es especialmente válido si se considera que la expansión dispersa de la ciudad no ha sido ajena al consumo de sus espacios naturales, donde

Aun considerando la mayor concentración de habitantes en el casco céntrico en contraste con el resto de las áreas suburbanas (Acevedo \& Del Popolo, 1994). 
conviven el deseo de muchos vecinos de vivir en el bosque y en la costa de los lagos, y la demanda de infraestructuras y usos urbanos que terminan conspirando contra la preservación del ecosistema que originalmente despertó el interés de vivir en él.

FIgura 4 Península San Pedro, 2013

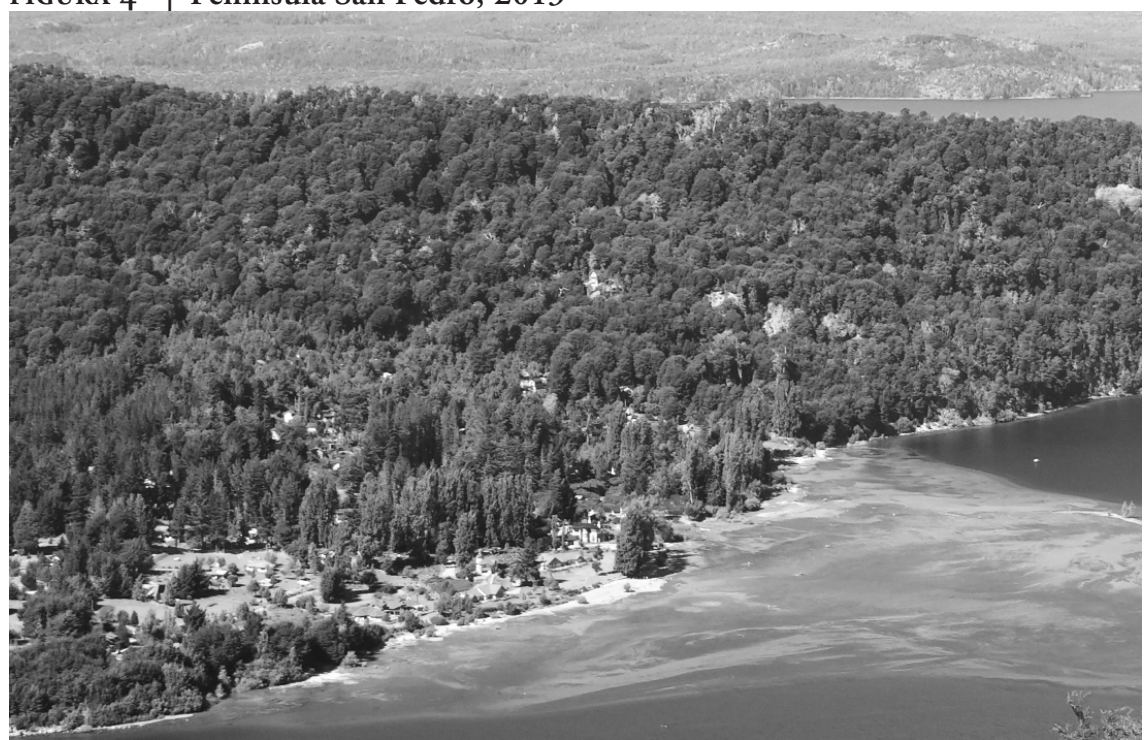

FUENTE FOTOGRAFÍA DE DAIANA BARDIN

Figura 5 | Península San Pedro, 2013

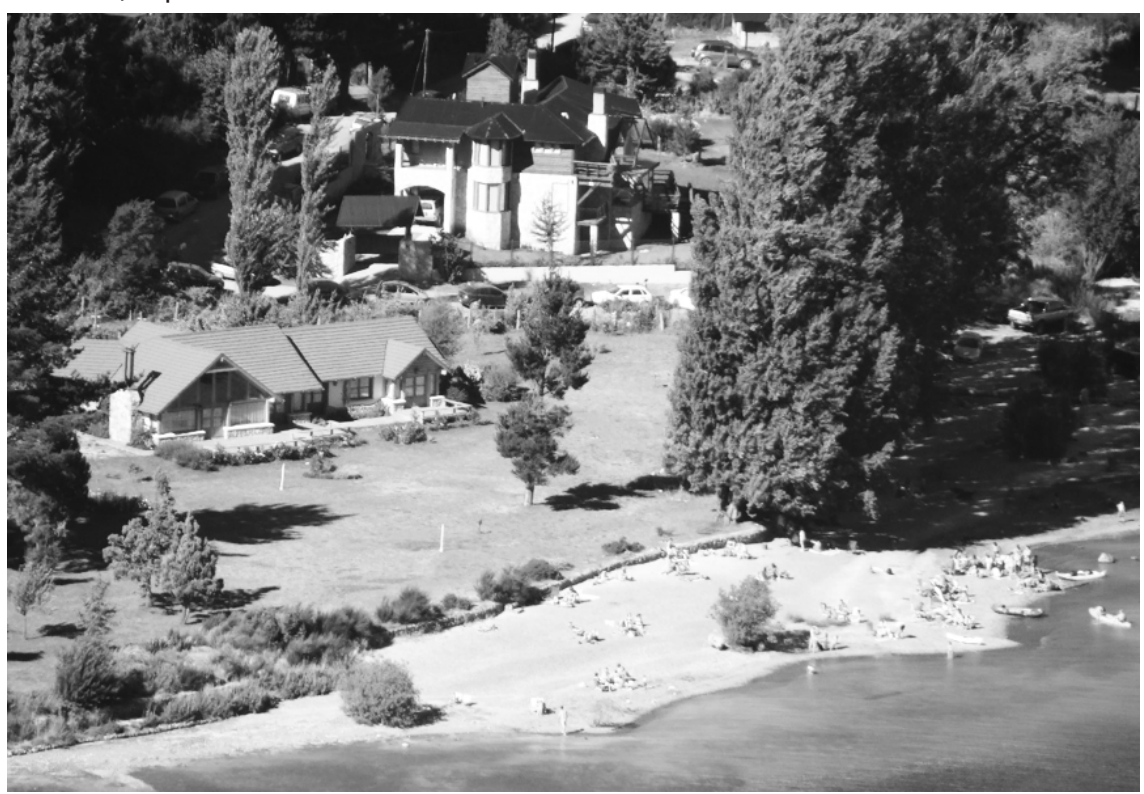

FUENTE FOTOGRAFÍA DE DAIANA BARDIN 


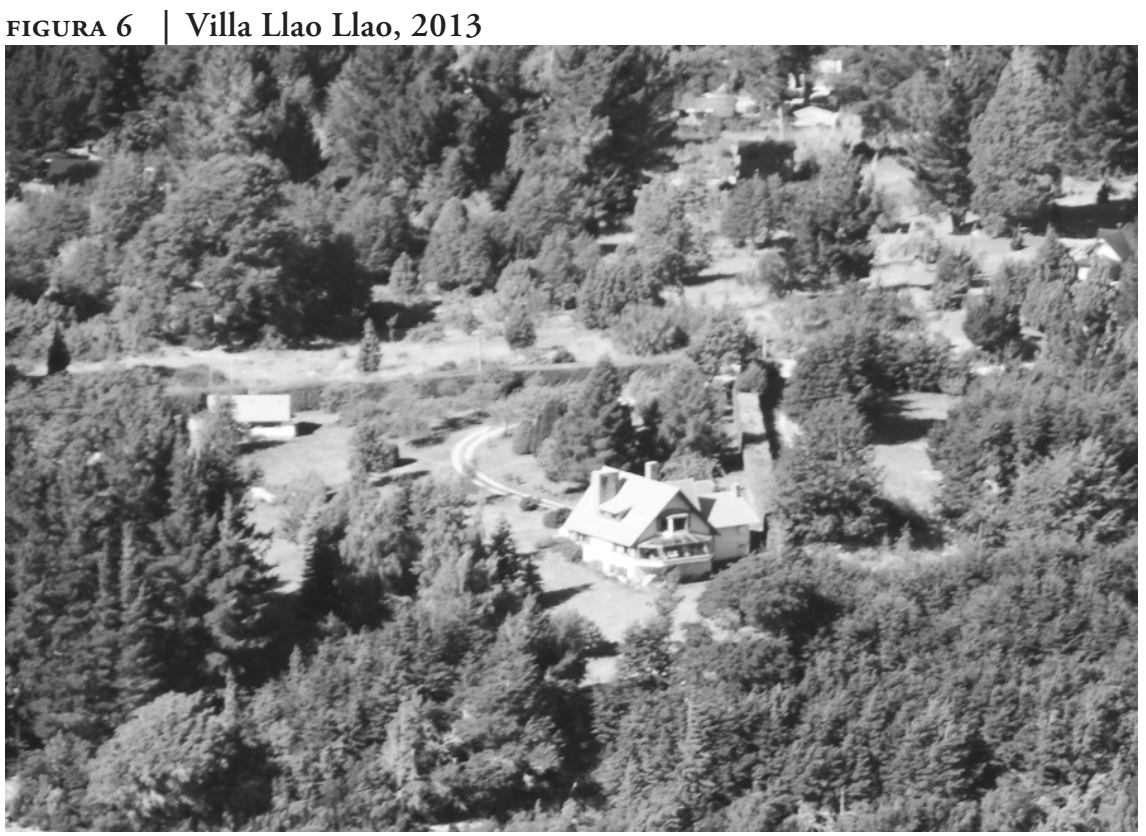

FUENTE FOTOGRAFÍA DE DAIANA BARDIN

El crecimiento poblacional, desordenado y difuso, ha implicado que en muchas áreas naturales de la ciudad se generen problemas ambientales por la ocupación de terrenos poco aptos para ser urbanizados (Pereyra et al., 2005). Así, la falta de previsión y de un orden territorial que tenga en cuenta las características del entorno físico han llevado a que se ocupen zonas anegables (como mallines y planicies de inundación) y se disponga de sitios no adecuados para la colocación de residuos, lo que ha generado en muchos casos la contaminación de las aguas (Pereyra et al., 2005, p. 79). Buena parte de las medidas regulatorias sostenidas en el Plan Director, y dispuestas normativamente en los códigos de planeamiento y edificación de 1980, fueron socavadas en su totalidad o poco a poco minadas mediante ordenanzas de excepción y artilugios que lograban eludirlas o reducir su impacto. Esto fue lo que ocurrió, por ejemplo, con la autorización de usos e indicadores urbanísticos en espacios naturales alejados del área urbana, que en función de lo normado debían conservarse o regenerarse, según el riesgo que presentaran. ${ }^{6}$ Por el contrario, los loteos

$6 \longdiv { \text { A solo tres años de aprobado el código de planeamiento, se asignaron nuevos usos e indicadores } }$ urbanísticos a gran parte de las subáreas de regeneración ecológica, localizadas predominantemente en el oeste y en zonas cercanas a lagos. Mediante la sanción de una ordenanza (5-o-83) se estipuló que los propietarios de lotes que contaran con infraestructura y determinados servicios públicos podían hacer uso de estos beneficios. Muchos pudieron acceder a ellos porque ya contaban con alguno de estos servicios o porque se organizaron colectivamente y demandaron por ellos al Municipio; a este respecto, ejercieron un rol fundamental muchas de las juntas vecinales que nacieron y se consolidaron en paralelo al crecimiento de los barrios. Entre ellos pueden mencionarse como ejemplos a Casa de Piedra y Pájaro Azul entre los km 12 y 15 de avenida Bustillo y, ya cerca del cerro Catedral, Villa los Coihues, que bordea los márgenes del lago 
que comenzaron a autorizarse de manera aislada en la década de 1940 siguieron marcando en ańos más recientes las tendencias de crecimiento en centros de servicios urbanos diseminados en el territorio (Rodríguez, 2015, p. 212).

Teniendo en cuenta que el suelo urbano no solo compromete una faceta productiva indispensable para el desarrollo de las actividades económicas en una ciudad, sino que también es un elemento de emplazamiento básico condensador de bienes y servicios útiles para la calidad de vida en sociedad, cabría preguntarse, teniendo en cuenta las cualidades naturales de Bariloche, qué fenómenos podrían guardar estrecha relación con la fisonomía espacial descrita y su dinámica inmobiliaria.

\section{Las migraciones de amenidad y los procesos de naturbanización}

Como ya han afirmado otros autores (González, Otero, Nakayama \& Marioni, 2009; Prados, 2006 y 2011), las áreas naturales se transformaron en un valor inmobiliario muy preciado y objeto de interés que decide el traslado y el asentamiento residencial permanente de muchas personas. Las llamadas migraciones de amenidad o amenity migration (Moss, 2006) refieren a esa tendencia, es decir, al crecimiento poblacional motorizado por personas que ven en las ciudades de notoria presencia ambiental-paisajística un sitio ideal para vivir. Esto se vincula a las características de un mercado inmobiliario complejo en el que, además de la demanda local, toman parte no solo los que ocasionalmente visitan la ciudad y cuentan con el privilegio de acceder a segundas residencias -el llamado turismo residenciado (Grippo \& Visciarelli, 2007)-, sino también aquellos que, habiendo sido turistas, deciden asentarse definitivamente en el lugar por la calidad natural del ambiente y la tranquilidad que les puede ofrecer.

Alternativamente, María José Prados Velasco introduce el término 'naturbanización' para caracterizar el efecto y la interacción que produce el crecimiento urbano en espacios naturales circundantes a Parques Nacionales (Prados Velasco, 2006, 2011; Prados Velasco \& Cunningham, 2002; y Prados Velasco \& Del Valle Ramos, 2010). Describe al respecto cómo en algunos sitios de España la desconcentración y movilización poblacional se dirigen hacia áreas de mayor atractivo natural y paisajístico (generalmente, aquellas que se encuentran cercanas o pertenecientes a la órbita de algún Parque Nacional). Señala como elementos definitorios del fenómeno un elevado crecimiento demográfico, consecuencia de un aumento significativo de la población migrante, y un entorno medioambiental y paisajístico reconocido socialmente en el territorio (Prados Velasco \& Del Valle Ramos, 2010). La contraurbanización, en tanto fenómeno que describe la desconcentración poblacional en las grandes ciudades por una pérdida en la calidad de vida, comportaría el trasfondo de estos procesos migratorios y el asentamiento de nuevos pobladores en estos espacios naturales (Prados Velasco \& Cunningham, 2002). En estos términos, la naturbanización describiría una dinámica relativamente actual de crecimiento poblacional basada

Gutiérrez. Luego sobrevinieron otras ordenanzas sobre aspectos más puntuales, y acaso más complementarios a esta última, como ser la habilitación de usos comerciales y de servicios sobre la avenida Bustillo, que también confluyeron en la consolidación urbanística de un área que el código originalmente pretendía preservar. 
en preferencias residenciales vinculadas a entornos naturales de reconocida calidad paisajística: "Si la contraurbanización cuestiona el protagonismo detentado por los grandes centros urbanos como focos de atracción demográfica, la naturbanización viene a explicar el atractivo de las áreas rurales de características especiales como lugares de ocio, trabajo y residencia” (Prados Velasco \& Cunningham, 2002, p. 428).

A diferencia del wildland-urban interface o wui, término utilizado por muchos ambientalistas para referir la incidencia antrópica de un área urbana en el medio físico (Brillinger, Autrey \& Cattaneo, 2009; De Torres Curth, Biscayart, Ghermandi \& Pfister, 2012; Theobald \& Romme, 2007), la naturbanización no puntualiza las consecuencias dañinas e imprevistas que puede tener la acción del hombre en la naturaleza, como, por ejemplo, la ignición forestal. Fundamentalmente, no parte de un problema ambiental para sindicar las causas urbanas, o relativas a la vida urbana, que afectan a un entorno natural que se pretende proteger. Más bien, es un concepto reciente (López Reyes, Rodríguez Lagos \& Cabrera, 2008) que se apoya en fenómenos migratorios específicos relacionados a un tipo de expansión habitacional compleja al interior de las ciudades, y de manifestaciones diversas que trascienden sus consecuencias ambientales. En tal sentido, por las movilidades poblacionales que involucran, la naturbanización y las migraciones de amenidad son conceptos muy sugerentes para entender la dinámica espacial de San Carlos de Bariloche. Si bien ambos aluden a procesos demográficos recientes, ayudan a comprender concomitantemente algunas características morfológicas del entramado espacial y su devenir histórico. Permiten entender no solo su crecimiento disperso y la ocupación de diversas áreas paisajísticamente estratégicas, sino también las tendencias especulativas que involucraron la apropiación de áreas cuya valorización se esperaba más temprano o más tarde y, por tanto, la demanda concurrente de no pocos interesados.

No es menor la cantidad de libros y artículos locales que refieren la importancia histórica del componente migratorio en el crecimiento demográfico de la ciudad, destacando algunos de ellos a los migrantes provenientes de Chile, de la línea sur de Río Negro o de Buenos Aires que llegan en búsqueda de nuevas oportunidades laborales (Abaleron, 1992; Kropff, 2002; Matossian, 2008; Méndez, 2010). Acevedo y Del Popolo (1994) informan que, de acuerdo con el Censo 1980, la mitad de la población de San Carlos de Bariloche había nacido en otra provincia o en algún país extranjero. Si se considera que dicho censo no contabilizaba a los rionegrinos nacidos fuera del ejido de la ciudad, puede estimarse que la participación de los migrantes internos en el total era aún mayor. Tan solo en lo que respecta a los migrantes externos (países limítrofes u otros), Bariloche superaba la media nacional: casi el 18\% de su población era extranjera, contra el $7 \%$ en todo el país (Acevedo \& Del Popolo, 1994 , p. 14). Aunque estas proporciones cambiarían en mayor o menor medida en los siguientes censos, no dejaron de reflejar las tendencias migratorias características de la ciudad. Así, si bien el Censo 1991 indicaba que había aumentado a poco más de la mitad (54\%) la proporción de habitantes nacidos en Bariloche o en la provincia de Río Negro, todavía existía, además de los migrantes internos, un alto número de migrantes externos: el 16\% de los habitantes había nacido en otro país, mientras que, a nivel nacional, esta proporción alcanzaba el 5\% (Instituto Nacional 
de Estadísticas y Censos [Indec], 1991). Ya en 2001, los nacidos en Bariloche y en la provincia ascendían al $66 \%$ de la población, siendo en conjunto cada vez menos los habitantes que habían nacido en otras provincias o en el extranjero; sin embargo, se mantenían todavía algunas distancias con los guarismos nacionales: mientras que solo el $4 \%$ de la población residente en el país era extranjera, en Bariloche alcanzaba el 11\% (Indec, 2001). ${ }^{7}$

Lo anterior revela un hecho histórico: Bariloche ha tenido -como otros destinos turísticos de renombre más reciente (Zingoni, Martínez \& Quartucci, 2007; González et al., 2009) - la particularidad de conformar un mercado inmobiliario atravesado por intereses que trascendieron largamente la oferta y demanda local. $\mathrm{Su}$ progresiva ascendencia como centro turístico de renombre nacional e internacional explica la proliferación de estos intereses en torno a la demanda inmobiliaria de muchos migrantes que, a la par de una motivación laboral, también fueron atraídos por su entorno natural.

Zingoni, Martínez y Quartucci (2007), refiriéndose a San Martín de los Andes, pero haciendo extensivo el concepto a otras ciudades turísticas de montańa, introducen el concepto de 'valor público', acuñado por Saavedra y Mokate, al destacar las cualidades propias de la ciudad:

El Valor Público se distingue de otros tipos de valor por ser percibido por la ciudadanía colectiva, o el conjunto de la sociedad. Es necesariamente consumido o disfrutado de manera colectiva. Las preferencias públicas necesariamente están en el corazón del valor público. No obstante, el "público" no se trata de una mera agregación de preferencias individuales, sino de una decisión colectiva con respecto a lo que es valioso y prioritario (y lo que debe ser producido) para el conjunto social. (Saavedra \& Mokate, 2004, citado en Zingoni, Martínez \& Quartucci, 2007, pp. 3-4)

Aunque Zingoni, Martínez y Quartucci (2007) señalan que es un valor intangible sostenido por las personas que habitan el lugar, por la ciudadanía colectiva, enumeran una serie de características locales que le otorgarían ese valor: así, figuran aspectos tales como la vista al lago Lacar, la primacía montaña / vegetación y la tranquilidad, entre los factores que podrían enumerarse. Otros autores, destacando las características únicas que presentan los destinos turísticos, también mencionan este valor:

Muchos de los destinos turísticos de montańa y playa de nuestro país reúnen las condiciones para generar en el imaginario colectivo la visión de un espacio de aldeas que comparten ciertos valores públicos comunes que ofrecen mejores oportunidades para el desarrollo humano. El valor se relaciona con la capacidad de generar gozo, deleite o bienestar, brota del calce entre necesidades y deseos y las oportunidades que se abren de los servicios que se ofrecen. El valor público se distingue de otros tipos de valor por ser percibido por la ciudadanía de manera colectiva. Las preferencias públicas necesariamente están en el corazón del valor de lo público. (González \& Otero, 2013, p. 3)

$7 \quad$ Cabe reiterar que, si bien se observaba una tendencia general a la baja del componente migratorio en el crecimiento demográfico de la ciudad, los datos censales seguían sin reportar las movilidades que podían haberse producido al interior de la provincia. 
Pues bien, en el caso de Bariloche deben también ser considerados los valores públicos que intervienen sobre las preferencias de las personas que residen en la ciudad. Puede especularse que los valores públicos ambientales formaron parte importante de las motivaciones que acompañaron los procesos migratorios, contribuyendo históricamente en la estructuración de sus condiciones urbanas actuales. Así, por ejemplo, el crecimiento hacia el oeste, con el serio riesgo que supuso (y supone) para la preservación de la vegetación autóctona y las áreas boscosas, no puede ser comprendido sin considerar el anhelo de confraternizar con la naturaleza y, particularmente, de apropiarse de la vista al lago Nahuel Huapi.

Siguiendo a Jaramillo (2009), entre el conjunto de rentas que tipifica, deben mencionarse las rentas secundarias, pues a partir de ellas puede interpretarse la orientación que ha tomado el crecimiento urbano de la ciudad. En mayor grado que las rentas primarias tipo I y tipo II, que se originan en las cualidades diferenciales del suelo para construir (que pueden ser geológicas / naturales o intensivas por la potencialidad de edificar en altura), las rentas secundarias en las ciudades adquieren suprema centralidad por la importancia que tiene el consumo del espacio construido, es decir, su circulación y, por ende, su localización en los diferentes puntos de la ciudad. Aunque la formación de este tipo de rentas se origina en todas las ciudades, en destinos turísticos de montaña como San Carlos de Bariloche pueden tener una influencia paradigmática en las áreas suburbanas, donde el valor público de la naturaleza impera como principal factor incidente de la ocupación del territorio y las rentas diferenciales que se pueden exigir. Esto es lo que distingue a esta ciudad de otras en donde el proceso de crecimiento tiende a ser más compacto y condicionado mayormente por la cercanía a las redes de infraestructura y los servicios públicos.

Debe destacarse, entonces, la importancia que adquiere la localización del suelo $y$, particularmente, el componente medioambiental en la formación de las rentas del suelo en las ciudades turísticas: en el caso de Bariloche, supone un atributo diferencial y distintivo que atraviesa el conjunto de los suelos situados en ella. Este componente acentúa el privilegio de la localización y el precio que se paga por el usufructo del suelo, haciendo de la ciudad un bien privado objeto de negocios que, anclado en la belleza del paisaje y las actividades lucrativas asociadas, contribuye a explicar los fraccionamientos autorizados en el pasado, pero también los precios de los inmuebles y las características de su crecimiento en el presente.

Estos aspectos también aclaran por qué el proceso de subdivisión de tierras y la extensión de su ejido ha sido tan desordenado y poco regulado, favoreciendo la dotación parcial y desigual de infraestructura y equipamiento urbano. Son muy pocos los barrios - generalmente, los cercanos al casco céntrico-que pueden jactarse de contar con suelo urbano debidamente acondicionado.

Ahora bien, tomando en cuenta lo dicho, ¿¿de qué modo podrían impactar en la actualidad los migrantes por amenidad? Considerando el crecimiento económico registrado luego de la devaluación de la moneda nacional en los tempranos años 2000 y su incidencia esperable en una economía local basada decididamente en la afluencia externa, ¿cómo pudieron hacerse presentes en la disposición espacial de San Carlos de Bariloche? Y con ello, ¿¿de qué manera las tendencias (dispersas) que históricamente caracterizaron el crecimiento de la urbe pudieron haberse reeditado? 


\section{Los ańos 2000 y la explosión inmobiliaria}

Con el fin de la convertibilidad y la paridad cambiaria 1 peso-1 dólar en el año 2002 comienza, luego de un periodo recesivo generalizado, a revitalizarse la economía argentina y, en el caso particular de San Carlos de Bariloche, haciéndolo a partir de la reactivación de la actividad turística. Esto catapultó el turismo a un mayor protagonismo escénico, que se tradujo en nuevos privilegios para el sector. Su influencia concreta en las políticas locales dejó su impronta en la sanción de la ordenanza 1344 del año 2003 (1344-cm-2003), que eximió del cumplimiento de parámetros urbanísticos a las obras de remodelación y/o refacción de edificaciones destinadas a uso hotelero. Entre los considerandos de la legislación se señalaba que la dinámica de las inversiones turísticas ameritaba eximir del tratamiento por rango tres a las edificaciones con destino hotelero. ${ }^{8}$ Esto significaba que las obras edilicias que no se ajustaran cabalmente a lo establecido en el código podían evitarse los tiempos de este proceso y aceptarse de igual forma. Esta concesión también comportaba en sí misma una sugerente señal acerca de cómo había crecido en general la actividad de la construcción luego de la devaluación de la moneda. A este respecto, un indicador más certero del repunte de esta actividad lo ofrecen los permisos de edificación, los mismos crecieron exponencialmente a principios de la década de 2000, durante los primeros años de la posconvertibilidad.

\section{FIGURA 7 Permisos de edificación otorgados por ańo y localidad, en la provincia de Río Negro, 2000-2010}

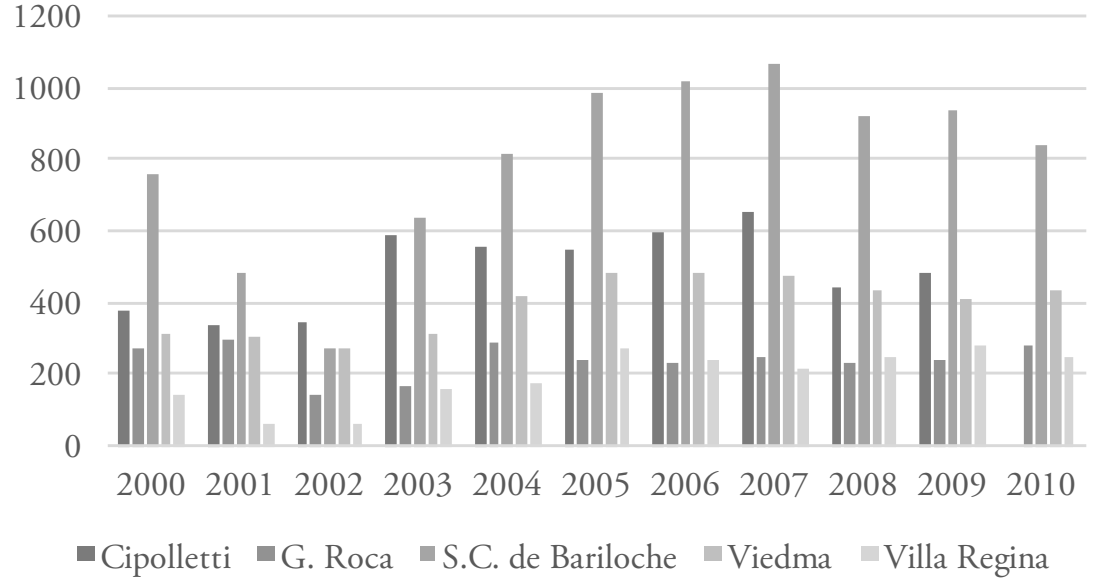

FUENTE ELABORACIÓN PERSONAL A PARTIR DE DATOS SUMINISTRADOS POR LA DIRECCIÓN GENERAL DE ESTADÍSTICAS Y CENSOS DE LA PROVINCIA DE RÍO NEGRO 
Además de ser San Carlos de Bariloche la principal solicitante entre el conjunto de las localidades rionegrinas, puede observarse cómo comenzó a experimentar desde 2003 un repunte extraordinario que, siendo mucho más significativo al año siguiente, se mantuvo en alza hasta 2007. Luego de haber alcanzado su mayor pico, la demanda igualmente se sostuvo en niveles que superaban los últimos años de la convertibilidad y los primeros que subsiguieron a la devaluación de 2002.

La superficie solicitada para edificar, que también se incrementó a pasos agigantados luego de ese año, integra complementariamente otro indicador de la dinámica del sector de la construcción.

Vale aclarar que tanto los permisos como la superficie requerida para la construcción no implican su concreción, es decir, la realización efectiva de las obras. Suponen, más bien, la expectativa de que pueden llegar a producirse. De todos modos, son muy útiles para reconocer la tendencia que sigue la actividad y el consabido efecto multiplicador que tiene sobre otros sectores de la economía. No obstante, aparte de ser indicadores del estado general de la actividad económica y dar cuenta del incremento de la demanda inmobiliaria local, los permisos de edificación y la superficie de edificación también sugieren la dinámica demográfica que pudo haber estado involucrada en su crecimiento. A nivel país, el crecimiento demográfico entre los años 2001 y 2010 fue de aproximadamente el 10,6\%, mientras que a nivel provincial supuso un ascenso del 15,5\%. En el caso de San Carlos de Bariloche, el crecimiento poblacional fue aún mayor que en los distritos mencionados, contabilizando un total de 112.887 habitantes, es decir, un porcentaje cercano al 21,2\% (Indec, 2010). ${ }^{?}$

FIGURA 8 | Superficie de construcción solicitada $\left(\mathrm{m}^{2}\right)$.

San Carlos de Bariloche, 2000-2010

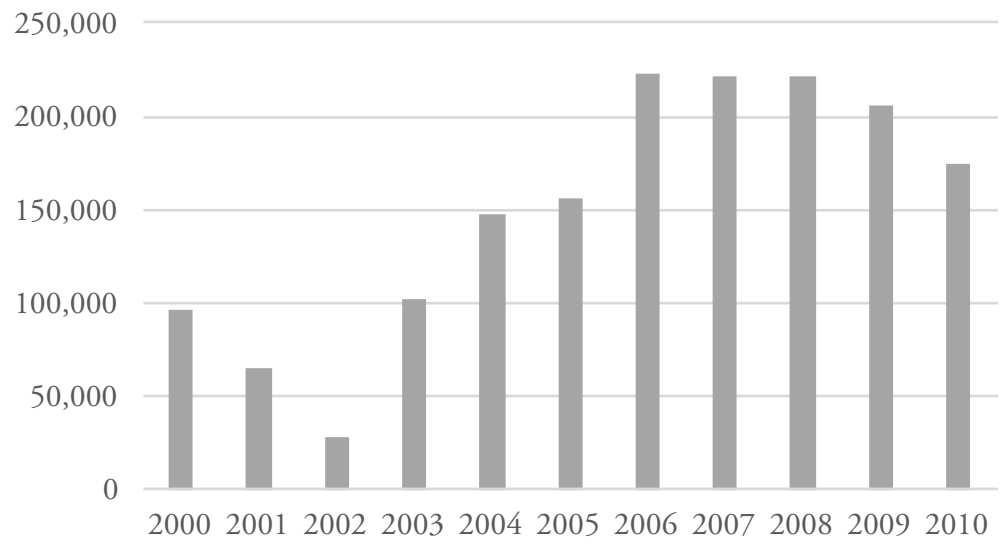

FUENTE ELABORACIÓN PERSONAL A PARTIR DE DATOS SUMINISTRADOS POR LA DIRECCIÓN GENERAL DE ESTADÍSTICAS Y CENSOS DE LA PROVINCIA DE RÍO NEGRO

9 Vale aclarar que la densidad poblacional no varió demasiado en el periodo: de 3,9 habitante por hectárea en 2001 ascendió a 4,1 en 2010. Debe mencionarse también que en 2005 se terminó de constituir el ejido actual, con la anexión de 2.885 hectáreas. 
Algunos agentes inmobiliarios atribuían este crecimiento a un aumento de migrantes provenientes de los grandes centros urbanos del país, que se sentían inseguros y huían en busca de una mejor calidad de vida:

Explotó mucho acá por toda la gente que se vino a partir de 2001, 2002, que fue la época de secuestros de Buenos Aires, de desesperación en las grandes ciudades, Rosario, Córdoba, Buenos Aires; toda esa parte empezó a emigrar de esos lugares. Empezó a venir mucha gente para acá. Nosotros teníamos una demanda de alquileres masivo. Había gente que por ahí dormía en los autos, me tocó a mí, por no encontrar lugar donde quedarse. (Rahal, 2012, entrevista)

La inseguridad en otros lugares hizo que la gente eligiera otros lugares para vivir. Y eso hizo que hubiera mucha inmigración. Me parece que esa fue una de las razones. (Fernández, 2011, entrevista).

Había mucha gente, hasta 2003, que venía buscando seguridad, tranquilidad; venía buscando eso. (Pena, 2012, entrevista)

Esta búsqueda, que también tuvo como protagonistas otros destinos turísticos, se canalizó de manera manifiesta en el incremento de la demanda inmobiliaria y las transacciones comerciales, que correlativamente implicaron un notorio aumento del precio de los bienes raíces durante esos años:

Mirá, después de la devaluación y después del corralito, las cosas empezaron a andar mucho mejor; es decir, en la época de la convertibilidad, en esa época estábamos con un 'párate’ bastante importante, porque el dólar no tenía valor. (Cavalieri, 2012, entrevista)

Nosotros tuvimos siete años espectaculares, que fue hasta el 2007, más o menos, en lo que era negocio inmobiliario; después se tranquilizó y volvimos a la normalidad. (Rahal, 2012, entrevista)

Yo te diría que los valores vinieron subiendo desde el 2007, 2005, fueron incrementándose los valores del metro cuadrado. Y ahora, desde hace un tiempo, yo te diría no mucho, antes de las cenizas, los precios empezaron a enfriarse un poquito. Desde el 2005 hasta el 2006 empezaron a subir hasta el año pasado, que llegó a un tope del metro cuadrado de los inmuebles. (Fernández, 2011, entrevista)

En la siguiente figura puede estimarse la evolución del precio promedio del suelo durante los primeros años de la década de 2000 y comienzos de la siguiente, cuando la devaluación de la moneda ya era un hecho consumado. La línea de tendencia se ha calculado considerando la oferta inmobiliaria de tierras libres de mejoras recogidas por la Oficina de Catastro Provincial en algunos barrios y áreas de la zona oeste. ${ }^{10}$

Como consecuencia de esta nueva explosión inmobiliaria que protagonizó la ciudad, emergieron las denominadas Reservas Naturales Urbanas que, en tanto iniciativas promovidas por vecinos, comenzaron a sellar su protagonismo a mediados de la década de 2000. Un mayor reconocimiento de la presión antrópica sobre el entorno natural y un mayor conocimiento de las causas y consecuencias de los

10 Los barrios y áreas registrados son: Villa Llao Llao, Villa Suyai, Parque Lago Moreno, Península San Pedro, Villa Campanario, Laguna El Trébol, Valle Escondido, Las Cartas y Colonia Suiza. 
peligros naturales confluyeron para que adquiriera mayor visibilidad esta problemática (Pereyra et al., 2005).

FIgURA 9 | Precio promedio del suelo ofertado (u $\left.\$ \mathrm{~s} / \mathrm{m}^{2}\right)$ en San Carlos de Bariloche, 2003-2012

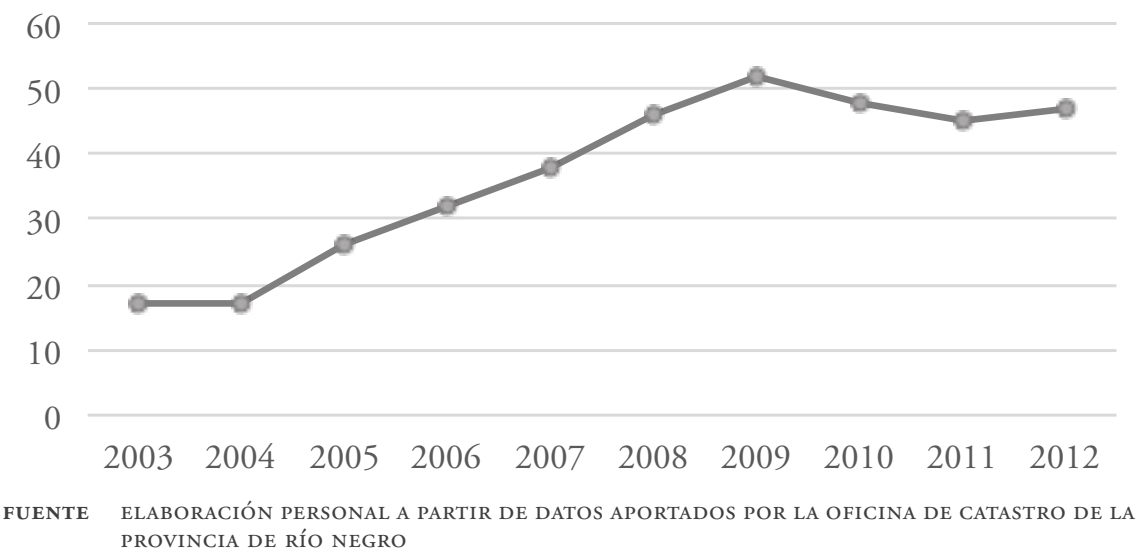

La reserva natural urbana Laguna El Trébol -ubicada al oeste del ejido y cercana a los recorridos turísticos- se convirtió en 2005, a instancias de los vecinos de dicho barrio, en la primera área de este tipo que fue aprobada por el Concejo Municipal (ordenanza 1570-cm-2005). Básicamente, la propuesta consistía en mantener una zona del barrio alejada de los efectos nocivos que podían traer aparejadas las nuevas construcciones y la urbanización de su entorno más inmediato. La conservación de la naturaleza proponía ser un objetivo que en defensa del medio, y ante la valorización de la tierra, procuraba evitar el desembarco de proyectos urbanísticos que pudieran atentar contra los atractivos naturales que inicialmente habían despertado el interés de sus habitantes por vivir allí.

Fue la primera, pero no la única, reacción paradójica de algunos vecinos de Bariloche ante el probable avance de comerciantes y nuevos residentes que, como ellos, también deseaban gozar de los beneficios del bosque, el lago (la laguna, en este caso) y la vista privilegiada que podía propiciar el hábitat natural de la ciudad. Así, surgieron otros proyectos similares, como las reservas naturales y urbanas Alto Jardín Botánico (ordenanza 1802-cm-2008) -más cercana al casco céntrico-, Lago Morenito y Laguna Ezquerra (ordenanza 2030-cm-2010) y Bosque de la Ermita (ordenanza 2082-cm-2010). Estas iniciativas terminaban convirtiéndose en una expresión más de la conflictiva y traumática relación de convivencia entre viejos y nuevos vecinos en una ciudad que, aunque crecía bajo el estímulo de sus atractivos naturales, simultáneamente también parecía correr el riesgo de perderlos. De esta forma, las Reservas Naturales Urbanas constituían una reacción contra los emprendimientos urbanos - con sus potenciales derivaciones en materia de equipamiento e infraestructura- en lugares que basaban su valor en la propiedad ambivalente de ser y no ser, en el valor de la naturaleza cuasi virgen y antropizada que es urbana y, a la vez, no lo es. 
Ahora bien, ¿̇en qué medida estas reservas podrían comportar casos aislados?, ¿no son acaso, más allá de las formalizaciones normativas que las particularizan, representativas de cierta tipicidad del suelo barilochense presente en muchos sectores habitacionales de su ejido?, ¿no terminan siendo una expresión elocuente de los límites a la urbanización (si se entiende por tal el proceso de provisión de determinadas redes de infraestructuras, servicios y equipamientos que se opone, fundamentalmente, a la fuerza de la naturaleza y la doblega) que singularizan y realizan al suelo de la ciudad -en su generalidad, más allá de los casos puntuales- y le otorgan su valor?

Topalov (1979) señala que el suelo urbano se diferencia del suelo rural por poseer un valor de uso específico y complejo, diferenciado del valor de uso de cada una de sus partes, que tiene un efecto concreto y útil de aglomeración. Estos valores que lo integran se corresponden en gran medida a bienes y servicios, suministrados mayormente por el Estado, que bajo la forma de infraestructura de servicios, vías de circulación, asfalto, etcétera, contribuyen a dotar al suelo de sus características urbanas. Jaramillo (2009) también define un conjunto de propiedades que pueden asociarse al valor de uso complejo que Topalov observa en las ciudades y que dotan a la tierra urbana de rasgos que la identifican y diferencian de la tierra rural. Ambos señalan que estos efectos útiles de aglomeración son apropiados por los dueńos de la tierra en forma de rentas urbanas, aunque, en el caso de Jaramillo, bajo una forma específica que define su base: la renta urbana absoluta. Sin embargo, estas características típicas del suelo urbano en las ciudades capitalistas no se corresponden del todo con el tipo de suelo que presenta la localidad andina. Es parcial su formación urbana: los valores de uso que lo articulan no han terminado de consolidarse y conviven con la naturaleza en gran parte de su territorio. Así, por ejemplo, algunos servicios públicos, como la red de gas, no llegan a los sitios más alejados; y otros, como la red cloacal, ni siquiera comprenden a los barrios más cercanos al centro de la ciudad, donde la provisión de este servicio debería encontrarse mayormente consolidada.

\section{Reflexiones finales}

Si bien la formación plena de los valores de uso complejo no forma parte de las características del suelo en San Carlos de Bariloche -o, al menos, no forma parte de sus características generales-, este no ha dejado de ser objeto de apropiación. Durante los ańos 2000 se constató el marcado dinamismo que tuvo la actividad de la construcción y la valorización creciente de los inmuebles. Contemplando cuáles han sido las principales áreas de ocupación en las que se han formado diversos aglomerados, dispersos y distantes entre sí, y la carencia o insuficiencia de infraestructura y de prestación de servicios urbanos en ellos, puede colegirse que el interés descansa en otros atributos del suelo, y que los efectos de aglomeración corresponden a otros determinantes. El entorno y el paisaje natural característicos de la ciudad han formado parte integral de las motivaciones de no pocos migrantes que, como señalaban los agentes inmobiliarios entrevistados, decidieron su traslado en busca de una mejor calidad de vida.

Son, en definitiva, los atractivos naturales inigualables de la región andina los que permitieron catapultar Bariloche como centro turístico y los que constituyen el valor público y natural de la ciudad. Son, además, atributos que derivan casi 
exclusivamente de la localización privilegiada del suelo en un entorno de por sí privilegiado y sumamente valorado -en algunas áreas más que en otras-, que no podría convivir o, mejor dicho, se vería negado en tanto tal por procesos de conversión urbana que pretendieran paliar los déficits en equipamiento e infraestructura. En este orden es que la opacidad transitiva entre el espacio urbano de la ciudad y su espacio natural, en tanto objeto de valor, constituye en sí misma una característica distintiva. Las áreas de reserva natural urbana representan una expresión reciente y notable de este aserto, que han adquirido relevancia por su formalización normativa, pero que no dejan de pertenecer a una lógica socioterritorial de ocupación histórica del paisaje y de reconocimiento de las bondades naturales locales.

En todo caso, la creación de estas áreas representa, por la propia contradicción que expresa el término natural-urbano, la acabada síntesis de ciertas características del suelo que permiten la apertura a nuevos interrogantes. Si en gran parte del ejido es expresa la urbanización parcial, o suburbanización, de algunas áreas donde el suelo, sin conservar plenamente sus propiedades naturales, tampoco logra desprenderse del todo de ellas, ¿cómo puede ser evaluado el tipo de valor de uso específico y complejo que tiene el suelo urbano y, sobre todo, sus efectos de aglomeración en una ciudad en la que, a pesar de su crecimiento demográfico, sigue siendo notoria la baja densidad poblacional y la dispersión de sus habitantes?

También cabe preguntar, teniendo en cuenta la singularidad del suelo en esta localidad andina, si la formación de una renta absoluta urbana puede encuadrar en estos términos, es decir, si exclusivamente se la debe considerar en tanto expresión de los "atributos urbanos" que señalan Topalov y Jaramillo. En consecuencia, es pertinente preguntarse por las intervenciones de la naturaleza y en qué medida esta compromete -valga la redundancia- la naturaleza del suelo urbano (y sus componentes) en San Carlos de Bariloche y en otras ciudades turísticas. En tal sentido, ¿Cómo podrían pensarse las rentas del suelo teniendo en cuenta la interrelación entre la naturaleza y lo urbano?, ¿cuáles serían sus determinantes y como podría ser entendida analíticamente la explotación del suelo en estas ciudades donde el componente de amenidad ambiental es altamente valorado?

Retomando a Prados, acaso pueda cobrar sustento como fenómeno generalizable $y$, por tanto, de estudio, la naturbanización y, en particular, el suelo naturbanizado y las rentas del suelo a él asociadas. Si los efectos de aglomeración están dados por sus condiciones ambientales, cabe entonces la introducción de nuevas categorías analíticas que den cuenta de estos rasgos y respondan a la morfología y crecimiento urbano de ciudades turísticas como Bariloche. Acaso pueda pensarse en un marco analítico que integre las migraciones de amenidad, el impacto territorial que acusan las ciudades orientadas a la actividad turística o que cuentan con un gran atractivo ambiental, y la teoría de la renta del suelo, para indagar en las características específicas que presentan ciudades de este tipo y la relación que mantienen con la naturaleza como fuentes de explotación de su suelo. Una nueva tipología de la renta del suelo debería poder responder a estas condiciones diferenciales de explotación que, referenciada en una renta absoluta urbana diferencial o renta del suelo naturbanizado, trascienda la condición urbana y se articule a las características naturales y ambientales propias de estas ciudades, estructurando la totalidad de las rentas del suelo (primarias y secundarias). 


\section{Referencias bibliográficas}

Abaleron, C. A. (1992). Tendencias de crecimiento poblacional y espacial en San Carlos de Bariloche con énfasis en el sectormarginal: Informe final. Consejo Federal de Inversiones (CFI)Municipalidad de San Carlos de Bariloche, Proyecto de Calidad de Vida de la Fundación BarilocheConicet. Mimeografiado.

Abaleron, C. A. \& Del Popolo, F. (1994). Dinámica demográfica y pobreza en San Carlos de Bariloche, Argentina. San Carlos de Bariloche, Argentina: Fundación Bariloche.

Acevedo, S. \& Del Popolo, F. (1994). Situación y dinámica demográfica de San Carlos de Bariloche. San Carlos de Bariloche, Argentina: Fundación Bariloche.

Anton Clavé, S. (1998). La urbanización turística. De la conquista del viaje a la reestructuración de la ciudad turística. Documents d'Anàlisi Geogràfica, 32, 17-43. http://www.raco.cat/ index.php/DocumentsAnalisi/article/download/31647/31481

Brillinger, D. R., Autrey, B. S. \& Cattaneo, M. D. (2009). Probabilistic risk modeling at the wildland urban interface: the 2003 Cedar Fire. Environmetrics, 20(6), 607-620. doi: 10.1002/env.959

De Torres Curth, M., Biscayart, C., Ghermandi, L. \& Pfister, G. (2012). Wildland-urban interface fires and socioeconomic conditions: A case study of a Northwestern Patagonia City. Environmental Management, 49(4), 876-891. doi: 10.1007/s00267-012-9825-6

González, R., Otero, A., Nakayama, L. \& Marioni, S. (2009). Las movilidades del turismo y las migraciones de amenidad: problemáticas y contradicciones en el desarrollo de centros turísticos de montańa. Revista de Geografía Norte Grande, (44), 75-92. http:// doi.org/10.4067/S0718-34022009000300004

González, R. \& Otero, A. (2013). El rol del Estado frente a los procesos de movilidad por estilos de vida en Argentina. Ponencia presentada en la edición 2012 de las Jornadas de Investigación y Extensión. Facultad de Turismo, Universidad Nacional del Comahue, Neuquén, 19 y 20 de abril de 2012. http://170.210.83.98:8080/jspui/ bitstream/123456789/127/1/gonzalez_rol_estado_frente_procesos_movilidad_por_ estilos_vida_argentina.pdf.

Grippo, S. \& Visciarelli, S. (2007). La acción territorializadora del turismo residenciado: su relación con las políticas públicas y la promoción inmobiliaria. Ciencias Sociales Online, 4(2), 1-14. http://www.uvm.cl/csonline/2007_2/pdf/Grippo-visciarelli.pdf.

Indovina, F. (2007). Antes de la ciudad difusa. En F. Indovina (Coord), Introducción a La ciudad de baja densidad. Lógicas, gestión y contención (pp. 13-23). Barcelona: Diputació Provincial de Barcelona, Xarxa de Municipis. http://www.diba.cat/pdfs/05531.pdf

Jaramillo González, S. (2009). Hacia una teoría de la renta del suelo urbano (2ª ed.). Bogotá D.c.: Universidad de los Andes, Facultad de Economía, Centro de Estudios sobre Desarrollo Económico (CEDE), Ediciones Uniandes.

Kropff, L. (2002). Juntas vecinales en Bariloche: una historia en disputa. Ponencia presentada en el Primer Encuentro Patagónico de Ciencias Sociales. Esquel, Chubut, República Argentina, 24-26 de octubre de 2002. 
López Reyes, V., Rodríguez Lagos, B. \& Cabrera, A. (2008). Análisis de procesos de naturbanización en parques naturales. En Los espacios rurales españoles en el nuevo siglo: Actas XIV Coloquio de Geografia Rural, Murcia, 22, 23 y 24 de septiembre de 2008 I coord. por José María Gómez Espín, Ramón Martínez Medina, 2008 (pp. 335-350). http://www.um.es/georuralmurcia/pdf/03_RODRIGUEZ.pdf

Matossian, B. (2008). Expansión urbana y conformación de barrios populares en San Carlos de Bariloche: el rol de las redes sociales de migrantes chilenos. Ponencia presentada en las 3as Jornadas de Historia de la Patagonia, San Carlos de Bariloche, 6-8 de noviembre de 2008. http://www.hechohistorico.com.ar/Trabajos/Jornadas\%20de\%20 Bariloche\%20-\%202008/Matossian.pdf

Méndez, L. (2010). Estado, frontera y turismo: Historia de San Carlos de Bariloche. Ciudad Autónoma de Buenos Aires: Prometeo Libros.

Moss, L. (2006). The amenity migrants. Seeking and sustaining mountains and their cultures. Trowbridge, Wiltshire, uk: Cromwell Press.

Pereyra, F., Albertoni, J., Bréard, C., Cavaliaro, S., Coccia, M., Ducós, E., ... Wilson, C. (2005). Estudio geocientífico aplicado al ordenamiento territorial de San Carlos de Bariloche. Buenos Aires: SEGEMAR-BGR, anales $\mathrm{N}^{\circ} 42$.

Prados Velasco, M. J. (2006). Los parques naturales como factor de atracción de la población: un estudio exploratorio sobre el fenómeno de la naturbanización en Andalucía. Cuadernos Geográficos, (38), 87-110. http://dialnet.unirioja.es/servlet/oaiart?codigo=2243265

Prados Velasco, M. J. (2011). Naturbanización. Algunos ejemplo en áreas de montaña y periurbanas. Treballs de la Sociedad Catalana de Geografia, (71-72), 179-200. http:// publicacions.iec.cat/repository/pdf/00000180/00000082.pdf

Prados Velasco, M. J. \& Cunningham, C. (2002). Calidad ambiental y nuevas pautas en la movilidad residencial de la población. Propuesta metodológica para el estudio de procesos de naturbanización. En XI Coloquio de Geografía Rural. Los espacios rurales entre el hoy y el mañana (pp. 425-433). Santander: Universidad de Cantabria. https:// idus.us.es/xmlui/bitstream/handle/11441/26715/calidad_ambiental_y_nuevas_ pautas.pdf?sequence $=1$ \&isAllowed $=y$

Prados Velasco, M. J. \& Del Valle Ramos, C. (2010). Naturbanización y cambios en la población de los espacios naturales de Doñana y Sierra Nevada. Documents d'anàlisi geográfica 56(3), 435-460. http://publicacions.iec.cat/repository/pdf/00000180/00000082.pdf.

Rodríguez, N. J. (2015). Efectos del crecimiento urbano en una ciudad turística de montańa. San Carlos de Bariloche, Patagonia Argentina. Investigaciones turísticas, (10), 202-230. https://dialnet.unirioja.es/servlet/articulo?codigo $=5289321$

Saavedra, J. J. \& Mokate, K. (2004). Gerencia social: Un enfoque integral para la gestión de politicas y programas sociales [versión preliminar]. Washington, DC: Banco Interamericano de Desarrollo, Instituto Interamericano para el Desarrollo Social. Versión definitiva publicada en Bogotá, Colombia: Programa de Apoyo a la Reforma de Salud (PArs) / Ministerio de la Protección Social (MPS), 2008. https://www.minsalud.gov.co/ Documentos\%20y\%20Publicaciones/GERENCIA\%20SOCIAL.pdf

Theobald, D. M. \& Romme, W. H. (2007). Expansion of the US wildland-urban interface. Landscape and Urban Planning, 83(4), 340-354. http://doi.org/10.1016/j. landurbplan.2007.06.002

Topalov, C. (1979). La urbanización capitalista. México, DF: Edicol. 
Zingoni, J., Martínez, S. \& Quartucci, E. (2007). Causas y efectos de la valorización del suelo urbano en destinos turísticos de la cordillera andino patagónica: El caso de San Martín de los Andes. Ciencias Sociales Online, 4(2), 37-53. http://www.ceproder.org/ aplicacion/showdocumento.php?id=121

\section{Fuentes consultadas}

Dirección General de Estadísticas y Censos de la Provincia de Río Negro. Edificación. Permisos de construcciones privadas y Obras públicas iniciadas. Año 2010.

Dirección de Catastro de la provincia de Río Negro.

Instituto Nacional de Estadísticas y Censos de la República Argentina (Indec). Censos nacionales de 1991, 2001 y 2010.

MunicipalidaddeSan Carlos de Bariloche. Concejo municipal. Digesto disponible en http://www. concejobariloche.gov.ar/index.php?option=com_wrapper\&view=wrapper\&Itemid=478

\section{Entrevistas realizadas}

Cavalieri, C. (2012). Entrevista realizada al agente inmobiliario Carlos Cavalieri.

Fernández, J. (2011). Entrevista realizada al agente inmobiliario Julio Fernández.

Orlandi, F. (2011). Entrevista efectuada a la exsecretaria de Planeamiento y Medio Ambiente de San Carlos de Bariloche, Fabiela Orlandi.

Pena, A. (2012). Entrevista realizada a la agente inmobiliaria Andrea Pena.

Rahal, N. (2012). Entrevista realizada a la agente inmobiliaria Nadia Rahal. 